\section{Die Röntgen Akademie für Führungskräfte in der Radiologie informiert:}

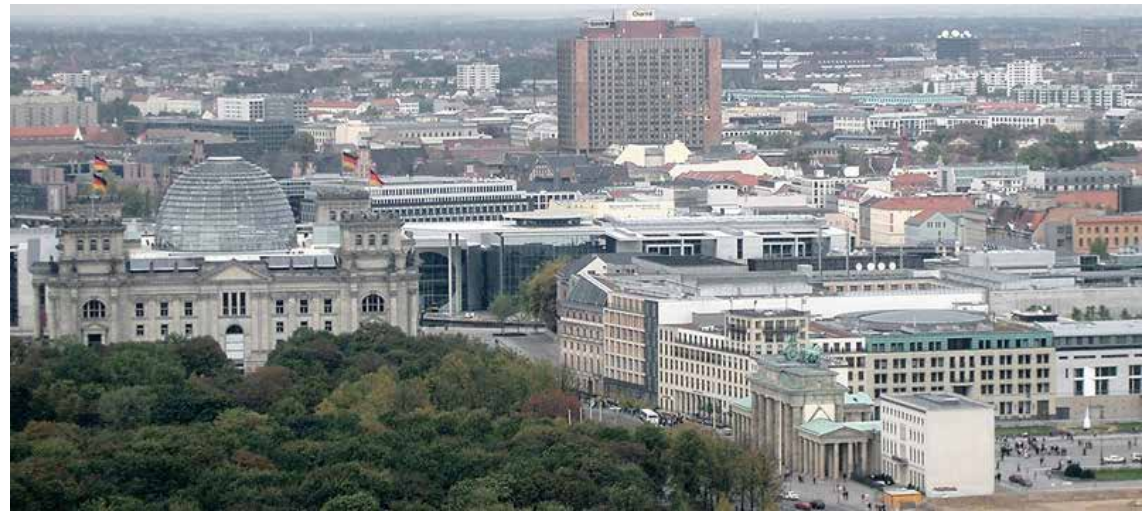

Stehen leitende Ärzte heute vor anderen Herausforderungen als vor 15 Jahren? Definitiv. Fachliche Qualifikation ist ein Muss, aber mangelnde Führungskompetenz inzwischen ein KO-Kriterium. Die Motivation, das verantwortliche, wirksame Führen von Mitarbeitern, sowie die Lösung von Konflikten am Arbeitsplatz werden zunehmend wichtiger.

Aus diesem Grund bietet die innerhalb der Deutschen Röntgengesellschaft in 2015 gegründete Röntgen Akademie für Führungskräfte in der Radiologie zum 2. Mal ein 2-tägiges hochprofessionelles Seminar für junge Chefärzte oder niedergelassene Radiologen mit folgenden Themenschwerpunkten an:

- Mitarbeiter- und Motivationsgespräche

- Grundlagen der Teamführung

- Konfliktmanagement

Gleichzeitig erhalten Sie die Möglichkeit zum Austausch mit anderen Seminarteilnehmern und Experten, die aus langjähriger Erfahrung berichten.

Wir freuen uns, dass wir für diese Fortbildung Herrn Jens Hollmann gewinnen konnten. Er ist Inhaber des Unternehmens medplus-kompetenz, Lehrbeauftragter an der Donau-Universität Krems, Coach und Berater für Ärzte und Klinikleitungen und bereits manch einem durch seinen Vortrag beim Chefarztforum (CAFRAD) bekannt.

Das Seminar findet vom 21. bis 22. Oktober 2016 in Berlin in exklusiver Atmosphäre im Hotel Pullman Schweizerhof statt. Reservieren Sie sich diesen Termin, denn der Führungsberuf Chefarzt mit seinen vielseitigen Aufgaben erfordert heute

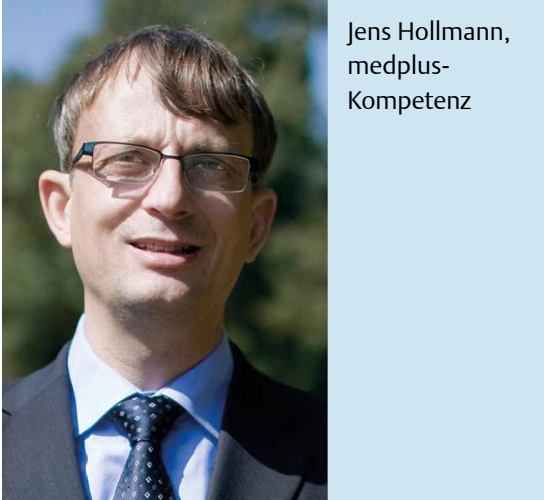

mehr denn je eine strukturierte Weiterbildung.

\section{Anmeldung}

Die Anmeldung zum Seminar ist bereits möglich über unseren Veranstaltungskalender unter www.drgakademie.de . Hier finden Sie auch detaillierte Informationen zur Röntgen Akademie für Führungskräfte, sowie einen Bericht über unser 1. Seminar im Sommer letzten Jahres.

Sollten wir Sie neugierig gemacht haben, steht Ihnen Frau Sabine Schlender in der Geschäftsstelle der Deutschen Röntgengesellschaft (email: schlender@drg.de, Tel.: 91607011) für Rückfragen gern zur Verfügung. 